\title{
O CORPO NEGRO, AS MARCAS E O TRAUMA ${ }^{1}$
}

\section{Sheila Cabo Geraldo UERJ}

\section{Resumo}

O discurso pós-colonial, de acordo com as teorias desenvolvidas a partir dos anos 1970, está nas marcas deixadas nas sociedades colonizadas, as quais construíram seus processos de independência e modernidade por cima dessas marcas, na forma da violência. A modernidade écomo uma máscara branca sobre a pele negra (Frantz Fanon), que só em casos de embate deixa aflorar, como imagens dialéticas, a permanência das relações escravistas recalcadas. São máscaras, impostas ou autoimpostas, que forçaram o apagamento da memória racial, muitas vezes associada ao gênero. $O$ texto aqui apresentado procura, assim, ativar criticamente algumas imagens produzidas pela artista Rosana Paulino, sobretudo as que desenvolveu para a instalação Assentamento, cujas imagens dos corpos masculinos e femininos escravizados, enquanto imagens de discursos científicos positivistas dos novecentos, são ressignificadas pela artista como imagens-denúncia.

\section{Palavras-chave:}

Corpo negro; Violência; Pós-colonial.

$\mathrm{Na}$ apresentação do livro Pele negra, máscaras brancas, $^{2}$ de Frantz Fanon, Jean-Paul Sartre escreve:

o que é que vocês esperavam quando tiraram a mordaça que fechessas bocas negras? Que elas entoassem hinos de louvação? Que as cabeças que nossos pais curvaram até o chão pela força, quando se erguessem, revelassem adoração nos olhos?

O livro de Fanon é seminal nos debates sobre o pensamento que conceitua o pós-colonialismo enquanto estudo dos rastros que as nações colonizadoras deixaram na cultura dos países que foram colonizados, mesmo depois de independentes. Foi principalmente a partir desse livro, publicado em 1951, que se passou a perguntar que marcas permaneceram como discriminações raciais e étnicas nos corpos de homens e mulheres

\section{Abstract}

The postcolonial discourse, according to the theories developed since the 1970s, is on the marks left in the colonized societies, which built their processes of independence and modernity over these marks, in the form of violence. Modernity is like a white mask on the black skin (Frantz Fanon), which only in cases of clash brings out, as dialectical images, the permanence of repressed slave relations. They are masks, imposed or self-imposed, which forced the erasure of racial memory, often associated with gender. The text presented here seeks to critically activate some images produced by the artist Rosana Paulino, especially those developed for the Settlement installation, whose images of male and female enslaved bodies, as images of positivist scientific discourses of the nineteenth century, are restated by the artist as images-complaint.

Keywords:

Black body; Violence; Postcolonial.

e que foram internalizadas como traumas. O livrotese de Fanon, um médico psiquiatra martinicano, que vivenciou em seu próprio corpo essas marcas e esse trauma, é ainda hoje uma referência no debate sobre a necessidade de ações reativas e busca pelo processo de descolonização. Como escreve Homi Bhabha, ${ }^{3}$ a força da visão de Fanon vem da tradição do oprimido, ativadora de uma linguagem revolucionária, a qual reconhece, assim como fez Walter Benjamin, que "o estado de emergência em que vivemos não é a exceção, mas a regra". ${ }^{4}$ (Fotos 1 e 2 )

A aquarela do escravo amordaçado de Debret, assim como as fotografias dos "tipos", do francosuíço Augusto Stahl, são algumas das imagens da violência sofrida (estado de exceção) pelos 


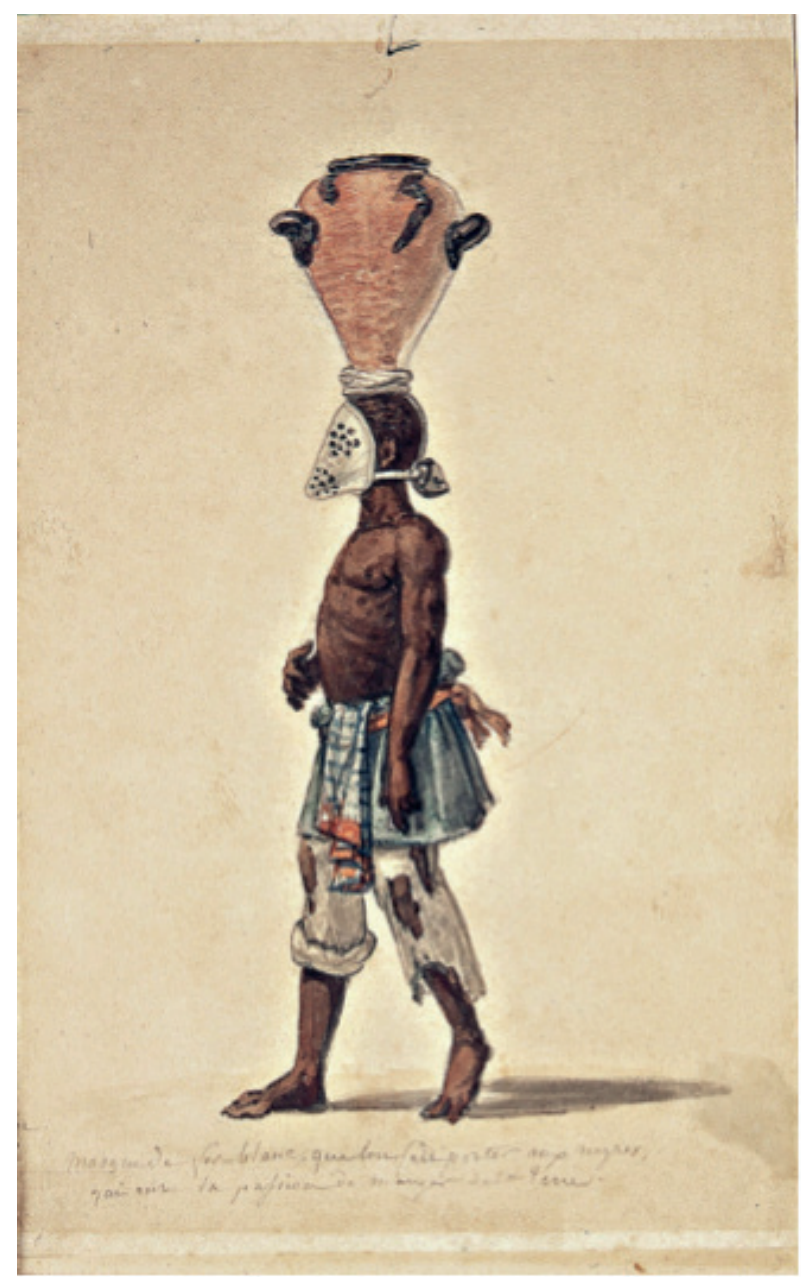

Figura 1 - Jean-Baptiste Debret. Negro com máscara. s/d.

corpos e mentes dos negros escravizados no período colonial brasileiro, que se mantiveram como latências e que eclodem em incontáveis momentos. No tempo presente, uma das mais significativas eclosões está nas gravuras e desenhos de Rosana Paulino, especialmente no trabalho Assentamento, que parte das fotos de Stahl encomendadas em 1865 e 1866 pelo naturalista suíço naturalizado norte-americano Louis Agassiz, cientista criacionista que fez estudos sobre miscigenação, catalogando os tipos de negros escravizados, acreditando ser possível provar pelos biotipos que os negros eram seres inferiores e que a miscigenação era uma forma de degeneração da espécie humana.

No livro Reise in Schwarz-Weiss: Schweizer Ortestermine in Sachen Sklaverei, Hans Fässler reproduz a carta que Agassiz escreve a sua mãe, quando estava na Filadélfia e se encontrara pela primeira vez com um afro-americano:
[...] senti pena à vista dessa raça degradada e degenerada, e compaixão pelo grupo, já que são, de fato, homens. Ainda assim, não consigo reprimir o sentimento de que eles não têm o mesmo sangue que nós. Ao ver seus rostos negros, com lábios grossos, dentes contorcidos e cabelo encarapinhado, seus joelhos arcados, suas mãos compridas, suas unhas curvadas e sobretudo a cor pálida das palmas das mãos, não consegui deixar de fitá-los, para garantir que ficassem bem longe. ${ }^{5}$

Agassiz veio ao Brasil em 1865 e em cidades como Rio de Janeiro e Manaus mandou fotografar dezenas de pessoas nuas, didaticamente arranjadas para representar a veracidade de suas teorias. ${ }^{6}$

\section{MEMÓRIA E TRAUMA}

As imagens de mulheres e homens fotografados por Stahl, nus, de frente, costas e lado - em um estudo étnico-antropológico de fundo racista -, que fazem aparecer homens e mulheres em posição de submissão e degradação, fazendo desaparecer sua humanidade, tal como Rosana reproduz em Assentamento, são imagensmemória do trauma que a escravidão deixou, mas são também a possibilidade de irrupções, em que se colocam os debates sobre a diáspora negra. Assentamento é originalmente uma instalação com reproduções em tamanho natural (altura da artista) das fotografias de Stahl - desconstruídas e reconstruídas com costuras propositalmente mal-acabadas, de fios soltos -, que retomam as imagens dos escravizados e das escravizadas para subvertê-las em desalinho, recusando seu fim e seu destino. As costuras, que remetem ao fazer feminino, estão sempre no campo do desvio, uma forma de resistência ao poder sobre o corpo, que se nega a se entregar por inteiro. 0 que a artista faz é costurar outro caminho, um devir afeto e sexualidade, na forma de um coração e um útero sobreposto, o que Ihes garantiria a sobrevivência da subjetividade. Rosana traz, assim, as fotos de Stahl para a história crítica da arte e da cultura, trazendo também a complexidade das latências, sobrevivências e sintomas, na forma de imagem das reminiscências de violência, que se atualizam em estado de crítica e crise, ou seja, como imagem dialética, que sempre abre, em choque, novos sentidos. O que faço, diz a artista, é focalizar a dignidade, a diversidade e o reconhecimento do capital cultural, artístico e religioso trazidos pela população africana. Mas, diz, ainda, sobretudo 


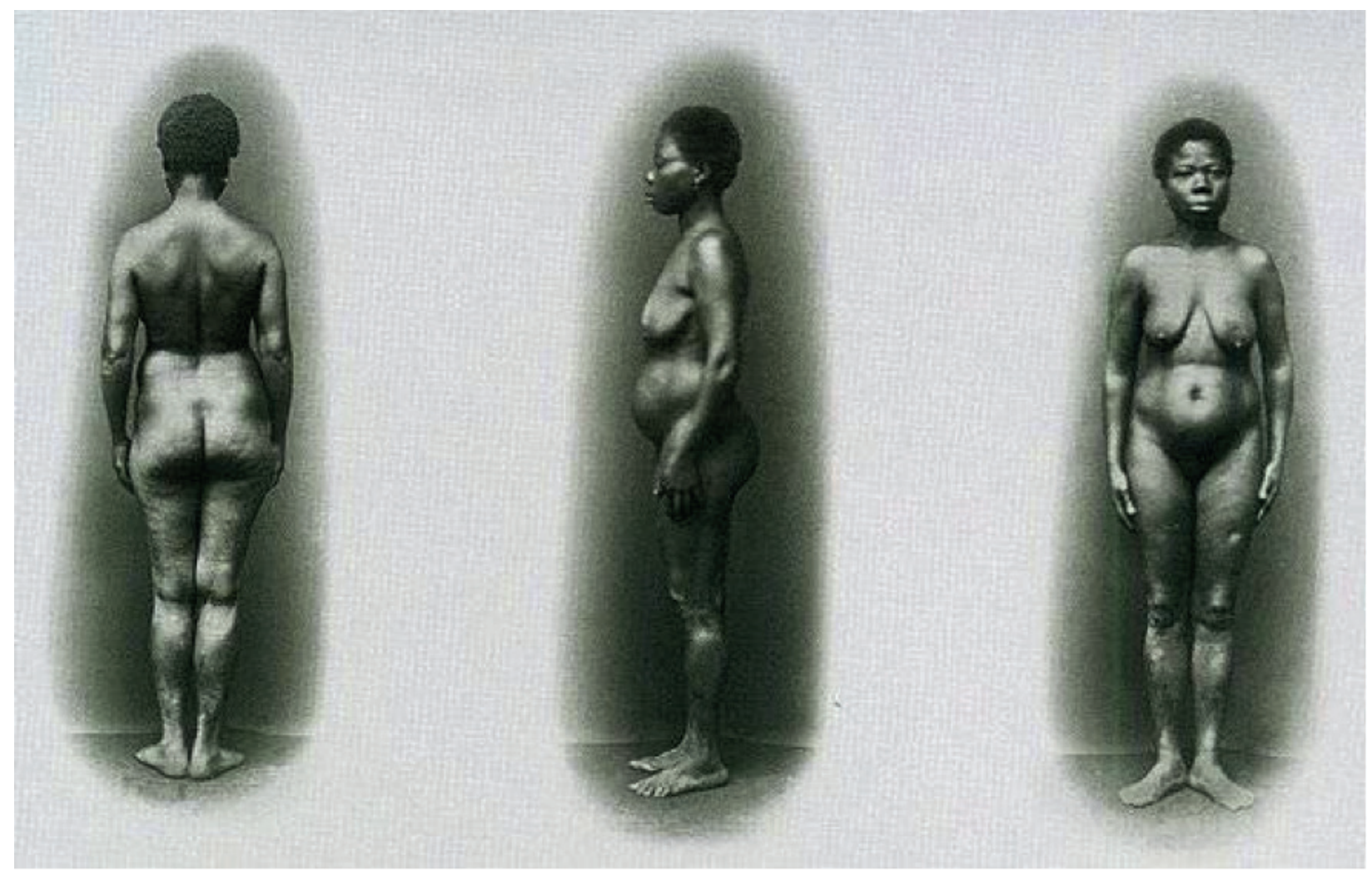

Figura 2 - August Stahl . Publicada em Ermakof, G. O negro na fotografia do século XIX. George Ermakof Casa Editorial 2004

"venho estudando o que é ser mulher e negra na sociedade brasileira", ${ }^{7}$ de longa tradição escravocrata, repleta de preconceitos não só raciais, mas também de gênero. (Fotos 3 e 4)

\section{O MOMENTO DE PERIGO SE REPETE}

Frantz Fanon, ${ }^{8}$ que era da llha da Martinica, negro, e que foi para a França estudar filosofia e psiquiatria, descreve um diálogo de quando chega à Europa:

_ Olhe o preto!... Mamãe, um preto!...

- Cale a boca, menino, ele vai se aborrecer!

Não ligue, monsieur, ele não sabe que o senhor é tão civilizado quanto nós; ${ }^{9}$

Evidentemente o perigo de que nos fala Benjamin nas Teses $^{10}$ não se restringia ao momento em que elas foram escritas, ou seja, a ascensão do nazifascismo. 0 perigo se repete sempre que a história está prestes a ser instrumento dos vencedores. Trata-se aqui da sobrevivência submersa do racismo e do preconceito, que afloram, como sintoma, não só nas palavras do menino francês, como escreve Fanon, mas também nas muitas imagens midiáticas contemporâneas a que temos acesso. Em 1983 o fotojornalista Luiz Morier fotografou o flagrante em que seis moradores negros de uma comunidade são presos por um PM e amarrados pelo pescoço como escravos humilhados. ${ }^{11}$ Em 2013 a Revista de História da Biblioteca Nacional publicou o vídeo Entre a suástica e a palmatória, baseado na pesquisa de doutorado de Sidney Aguilar Filho sobre a vida de meninos órfãos, em sua maioria negros, que nas décadas de 1930 e 1940 foram mantidos em regime de escravidão em fazendas do interior de São Paulo. Segundo matéria do dossiê Nazismo no Brasil, ${ }^{12}$ os proprietários, que por algum tempo foram integralistas, ajudaram a infiltrar no país as ideologias nazistas por meio de práticas e simbologias, como ficou registrado na bandeira do time de futebol da fazenda e nos tijolos encontrados por seu atual dono. ${ }^{13}$ Em 2016 foi publicada a fotografia de um casal que se dirigia a uma manifestação política e se fazia acompanhar por uma serviçal negra, uniformizada, de branco, empurrando um carrinho de bebê com o filho dos patrões, como faziam mucamas escravizadas nos séculos XVIII e XIX. (Foto 5) 


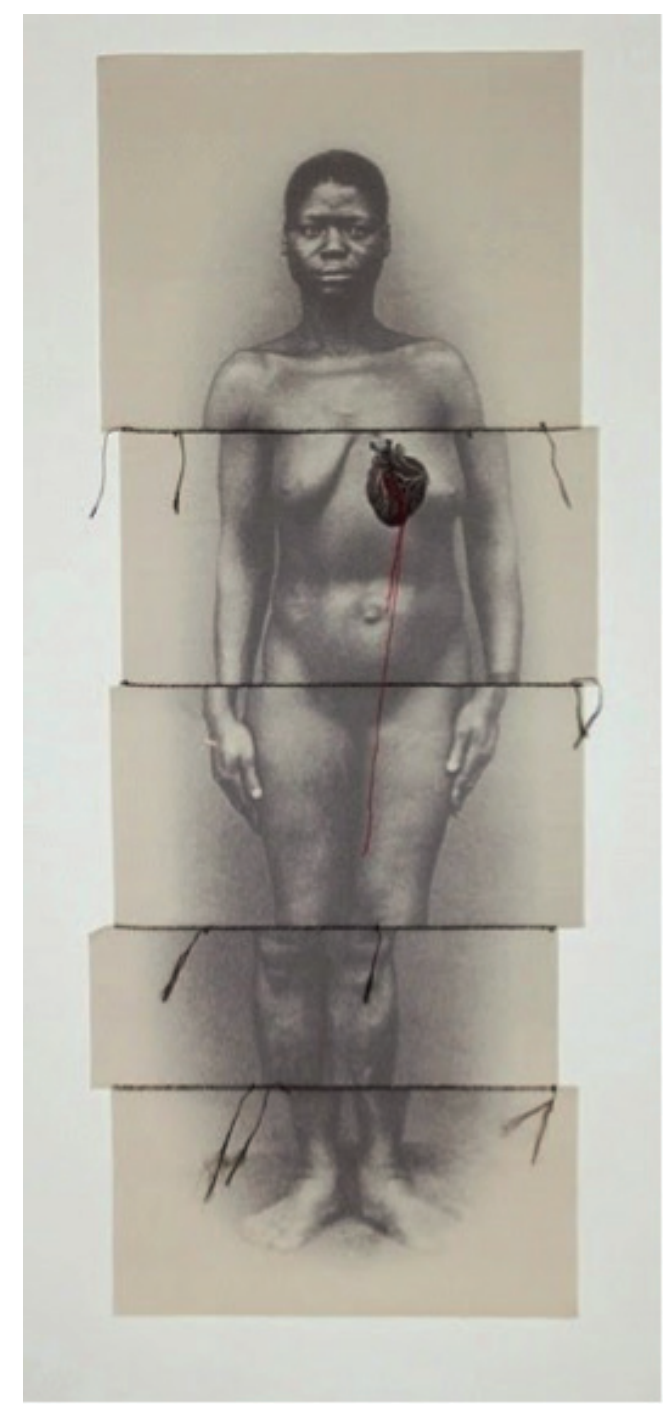

Figura 3 - Rosana Paulino. Assentamento 2014-2016

Em 1995, Rosana então iniciando sua carreira de artista fez uma série de gravuras ${ }^{14}$ em que o foco recai no debate sobre a mulher negra e, como escreve Fanon, nas "máscaras brancas" eventualmente adotadas para ser aceitas na sociedade branca e misógina. É tão fácil ser feliz, está escrito na parte de cima de uma das gravuras de Rosana. Para tanto, só falta adotar os hábitos e costumes que remetem ao mundo burguês-colonial. O que Rosana já pesquisa desde então faz referência a outro mundo, a um mundo de memórias de uma descendente de escravos, a quem foram negadas até mesmo as recordações. Na série de bordados Bastidor, de 1997, Paulino trata dos direitos da mulher negra que são reiteradamente negados. Ali, sobre reproduções de imagens transpostas para tecidos

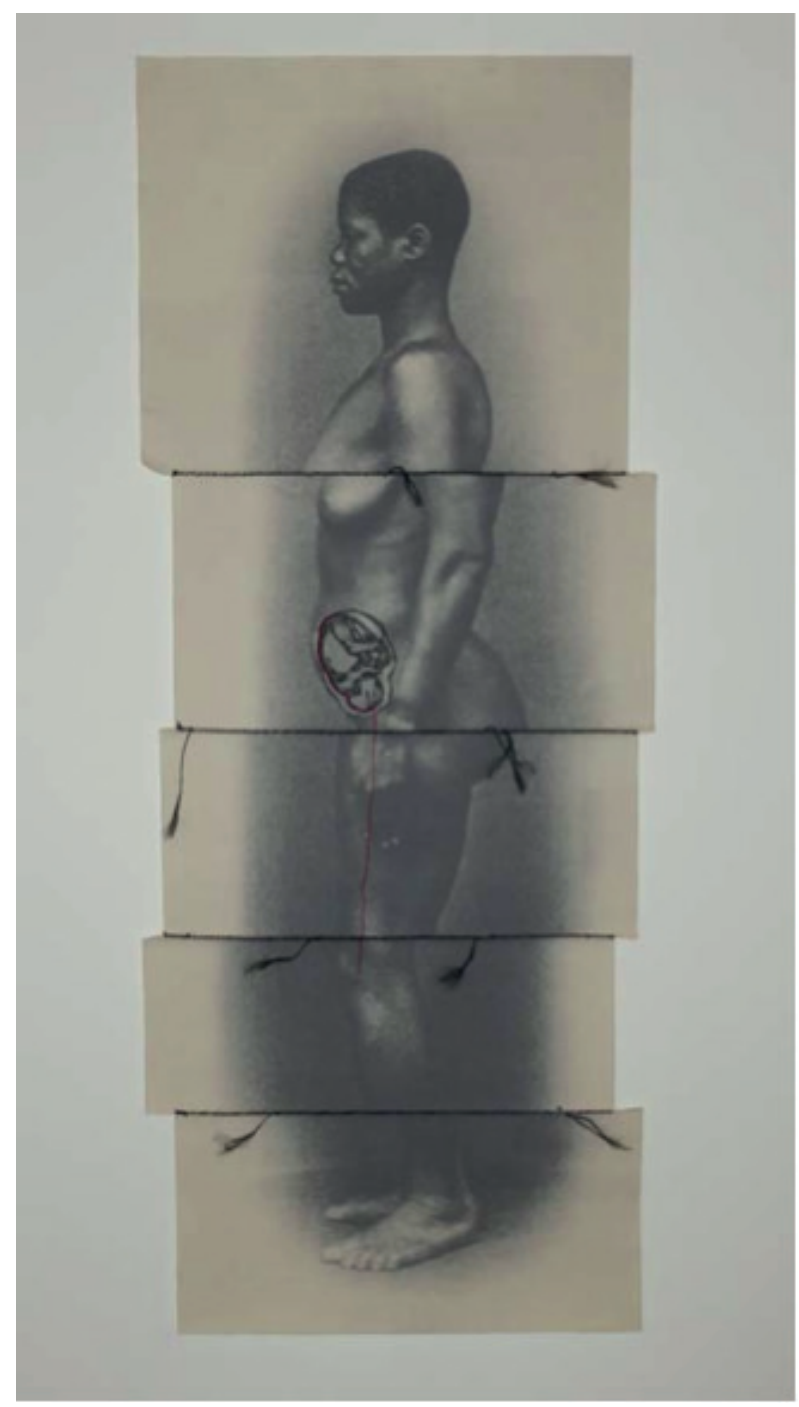

Figura 4 - Rosana Paulino. Assentamento 2014-2016

esticados em bastidores de bordado - uma tarefa tradicionalmente associada ao feminino -, são bordados, como sutura, bocas, olhos e gargantas, signos da violência sofrida ainda hoje - muitas vezes doméstica -, impossibilitando o discurso, que inevitavelmente afirmaria sua condição de negra e mulher. Resta-lhe um corpo bruto, anulado dos sentidos e da linguagem. (Foto 6)

\section{ENFRENTAR O CORPO COMO NEGAÇÃO}

Em Pele negra, máscaras brancas, Fanon registra, ainda, que no mundo branco o homem de cor encontra dificuldades na elaboração de seu esquema corporal, uma vez que em torno do corpo negro reina sempre uma atmosfera densa de incertezas. Do ponto de vista fenomenológico, 


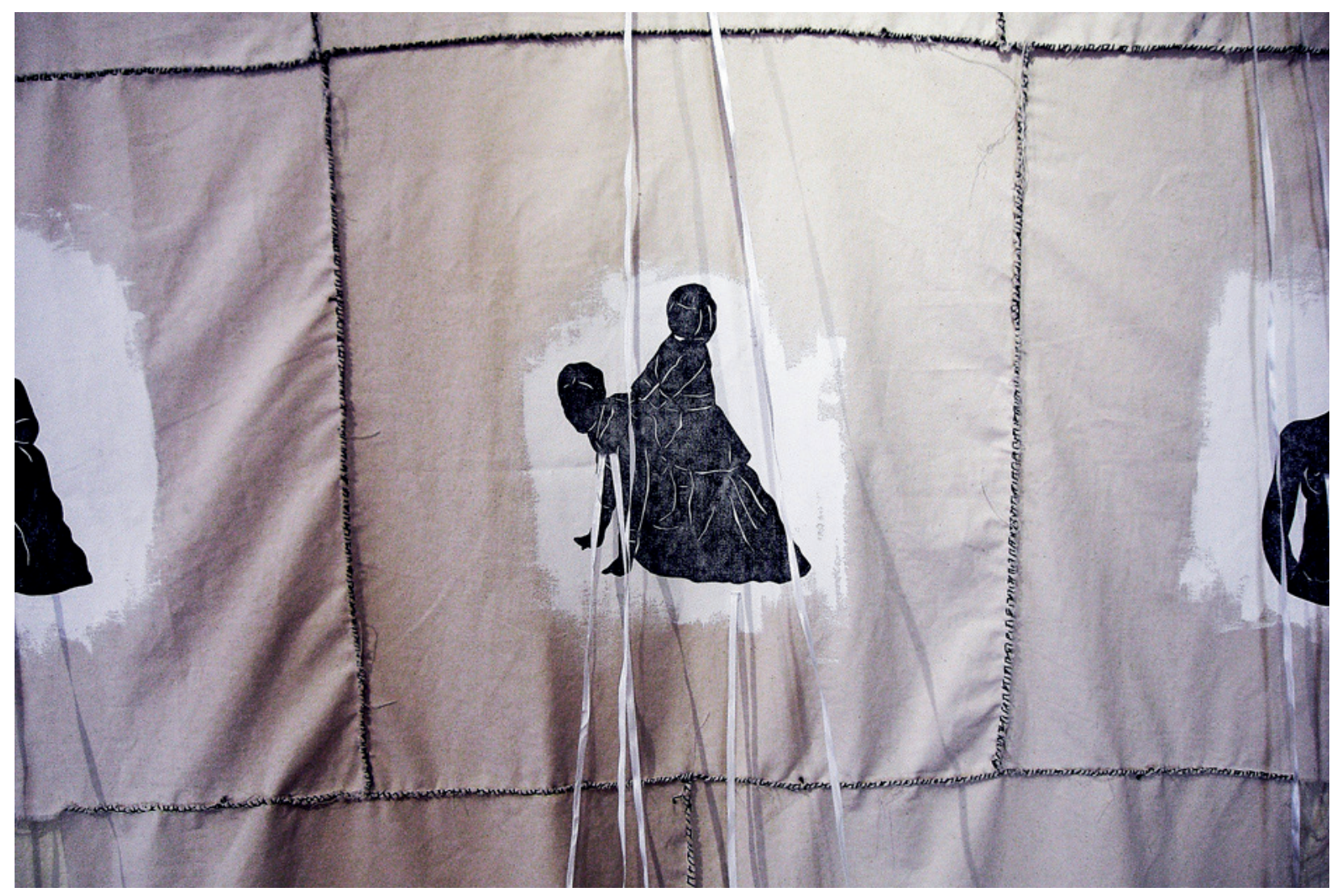

Figura 5 - Rosana Paulino. Ama de leite. (Detalhe) 2017

na construção do eu enquanto corpo no mundo espacial e temporal, haveria uma estruturação do eu e do mundo em que nenhum esquema se imporia, pois entre meu corpo e o mundo se estabeleceria uma dialética efetiva. Entretanto, observa o autor, para o homem negro, abaixo do esquema corporal há um esquema históricoracial. O esquema corporal desmorona, cedendo lugar a um esquema epidérmico-racial. A partir de suas vivências em transportes públicos na França, onde seu corpo negro estava sempre rodeado de vazio, percebe que sempre ocupava três lugares, já que ninguém se sentava ao seu lado.

Elaborei, abaixo do esquema corporal, um esquema histórico-racial. Os elementos que utilizei não me foram fornecidos pelos "resíduos de sensações e percepções de ordem sobretudo táctil, espacial, cinestésica e visual" mas pelo outro, o branco, que os teceu para mim através de mil detalhes, anedotas, relatos. ${ }^{15}$

Com base na noção lacaniana de estádio do espelho, ${ }^{16}$ Fanon se pergunta em que medida a imago do semelhante, construída pelo jovem branco, não sofre uma agressão imaginária com o aparecimento do negro. ${ }^{17}$ Uma vez entendido o processo descrito por Lacan, não há dúvida de que o verdadeiro outro do branco é e permanence sendo o negro. E inversamente. Só que para o branco, o outro é percebido como não lugar, isto é, o não identificável, o não assimilável. ${ }^{18}$

Fanon é descrito por Stuart Hall ${ }^{19}$ como um pioneiro do movimento de descolonização. Seus livros, declara Hall, até hoje nos desafiam a nos liberar da dominação psicológica implícita na relação colonizador/colonizado. 0 processo de descolonização a que se refere Hall se desenvolveu efetivamente a partir da segunda metade do século $X X$, quando os chamados países não alinhados se reuniram para reclamar protagonismo no cenário internacional. Um marco nessa trajetória é a Conferência de Bandung, na Indonésia, em 1955, que congregou países da África e Ásia recentementeindependentes paradiscutir políticas de descolonização, que thes possibilitassem desprender-se das macronarrativas ocidentais. Após seis anos, em outra conferência, dessa vez em Belgrado, participaram também Cuba e alguns países da América Latina. As contestações são acentuadamente econômicas e políticas, 


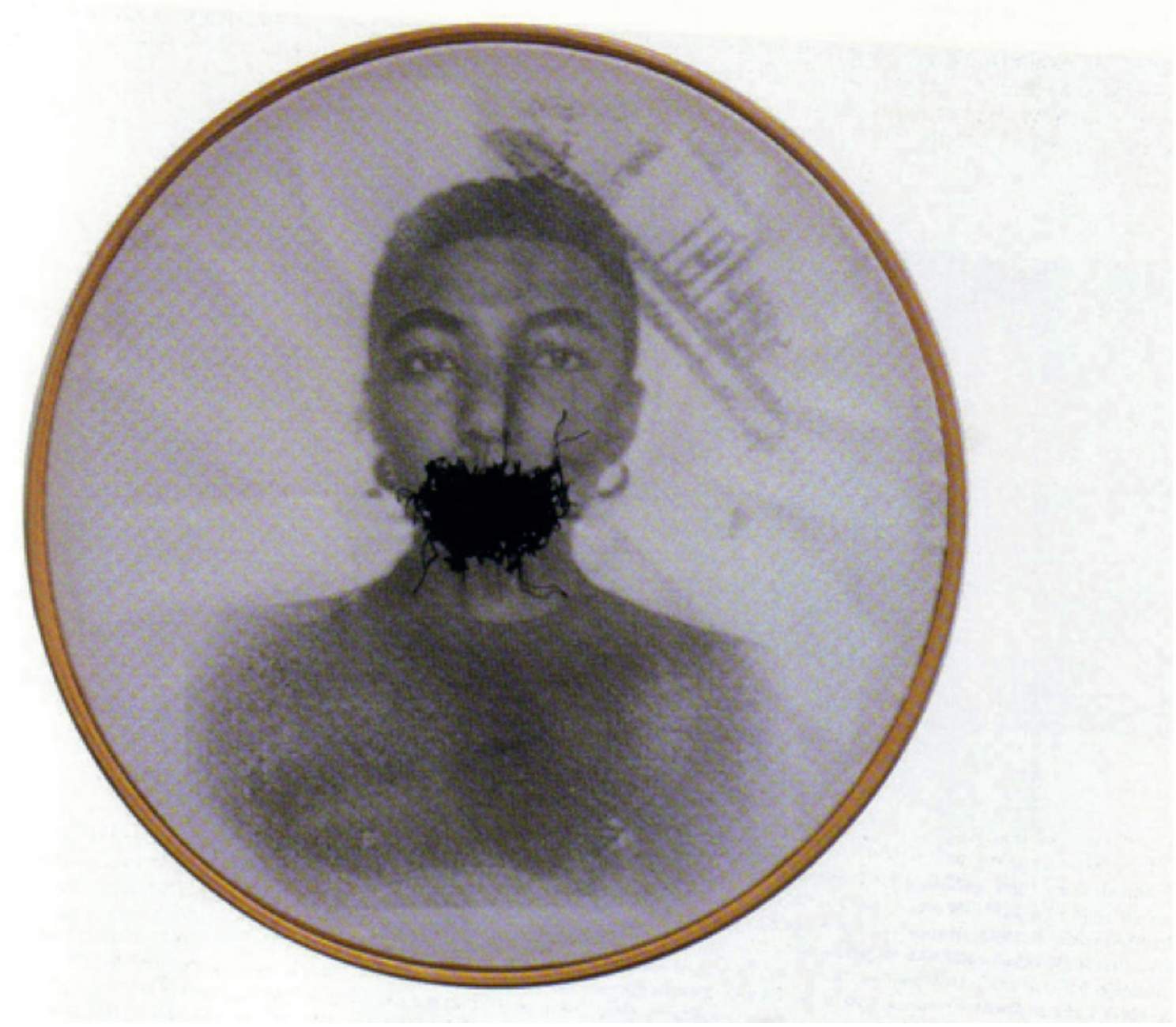

Figura 6 - Rosana Paulino. Bastidor

mas também artísticas e culturais. Sobretudo é nesse momento que novas matrizes de pensamento passam a colocar em xeque o sentido de modernidade, que se difundiu a partir do pensamento ocidental imperialista e colonialista. 20 Esse movimento é contemporâneo da diáspora nos Estados Unidos e na Europa, que corresponde ao crescimento de movimentos de "minorias". Como explica Stuart Hall, ${ }^{21}$ movimentos que alcançavam o feminismo das mulheres, as políticas sexuais dos gays e lésbicas, as lutas antirracistas dos negros, o movimento dos antibelicistas e dos pacifistas, etc.

O trabalho de Rosana Paulino, cujas imagens do corpo negro, sobretudo da mulher negra, lança importantes perguntas sobre a possibilidade de uma cultura e uma história da arte no Brasil que não seja a colonizada, abre-nos para os desafios que os textos de Fanon inaugura e que se anunciam como descolonização dos corpos e do pensamento. Como argumenta Fanon, "o negro não deve mais ser colocado diante deste dilema: branquear ou desaparecer, ele deve poder tomar consciência de uma nova possibilidade de existir".22

Assim como nos muitos desenhos em que se desdobra a instalação Assentamento, em que corpos racializados são bordados com as raízes da memória negra e da violência vermelha da colonização escravocrata, ressalta-se a organização do livro em tecido Atlântico Vermelho, em que Rosana costura uma nova possibilidade de existir enfrentando a diversidade do processo implícito na descolonização, montando outra história anacrônica e a contrapelo, que junta imagens da mulher negra e seus fantasmas, das navegações e do tráfico de escravos, da bela cultura tradicional portuguesa dos azulejos e da violência contra os escravos. 


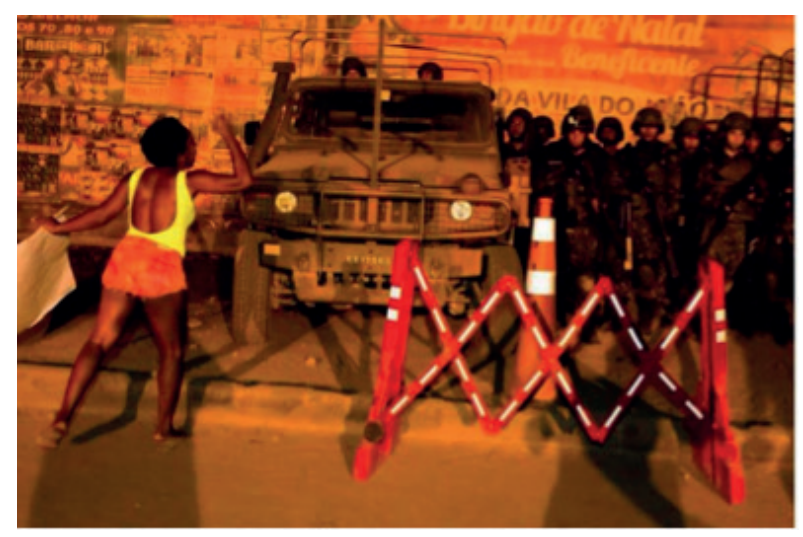

Figura 7 - Naldinho. Danielly 2014

É ainda, entretanto, por meio dos trabalhos de Rosana que chegamos a outro campo de reflexões, atingindo outras plataformas em que se evidenciam, também, outros artistas e outras obras contemporâneas. O que se coloca aqui como campo reflexivo vem inexoravelmente do deslocamento entre o impacto psicológico violento do racismo e a consequente reação, que corresponde a uma aposta na defesa da "negritude", o que implica um problema também identificado por Fanon, que ele classifica como um "enclausuramento no passado", impedindo outra maneira de estar no mundo por parte daqueles que chama de desalienados. Como escreveu:

De modo algum devo me empenhar em ressuscitar uma civilização negra injustamente ignorada. Não sou homem de passados. Não quero cantar o passado às custa do meu presente e do meu devir [;] Mas posso também recuperar meu passado, valorizá-lo ou condená-lo, através de minhas opções sucessivas. ${ }^{23}$

Em Frantz Fanon e a prerrogativa pós-colonial, Homi Bhabha ${ }^{24}$ nos relata que o martinicano é o provedor de uma verdade transgressiva e transnacional, que fala "a partir dos insterstícios incertos da mudança histórica;", uma área de ambivalência entre raça e sexualidade, de contradição entre cultura e classe, de conflito entre representação psíquica e realidade social. Fanon realiza um deslocamento no alinhamento colonial, que contrapõe negros e brancos; Eu e outro, apontando para uma extremidade cortante, que "expunha uma declividade completamente nua, de onde pode nascer uma autêntica sublevação". ${ }^{25}$

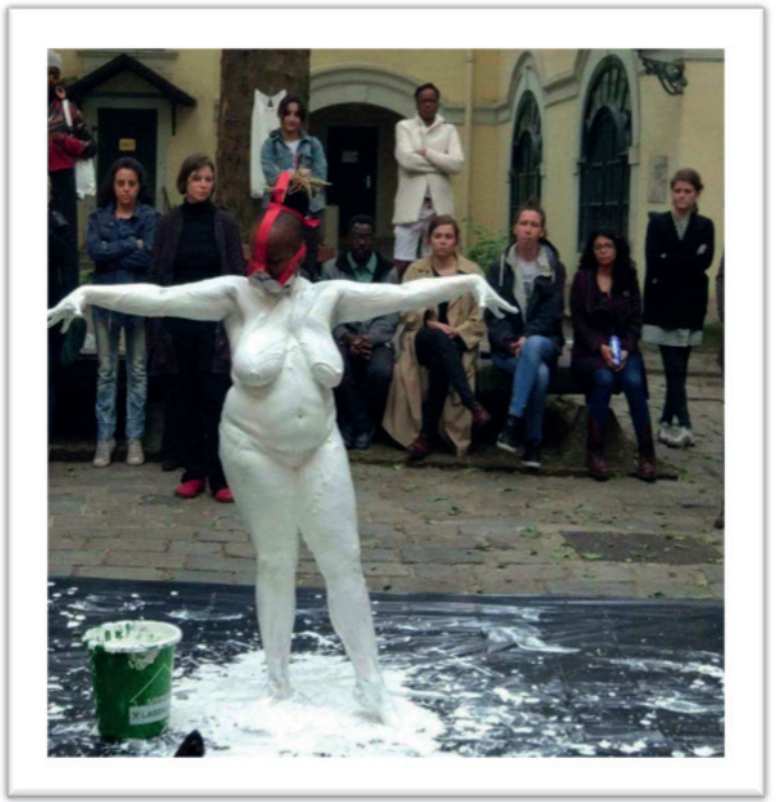

Figura 8 - Musa Michelle Mattiuzzi - "Merci Beaucoup,blanco!" Vienna Photo: Stephanie Misa. Maio, 2017.

\section{Ô MEU CORPO, FAÇA SEMPRE DE MIM UM HOMEM QUE QUESTIONA! ${ }^{26}$}

A questão da identidade da cultura negra levantada por Fanon está no cerne do ensaio de Stuart Hall, em cujo título pergunta: Que negro é esse na cultura negra? ${ }^{27}$ Hall questiona qual garantia uma identidade essencializada pode dar de ser simultaneamente libertadora e progressista. Considerando criticamente, ressalta que a identidade negra é sempre atravessada por outras identidades, como as de gênero e orientação sexual. Nesse sentido, as políticas culturais e a luta que incorporam se travam em muitas frentes. A questão da negritude é também abordada pelo filósofo camarones Achille Mbembe. No texto Afropolitanismo, ${ }^{28}$ Mbembe cita o escritor malinês Yambo Ouologuem, que não só critica os conceitos de origem, nascimento e genealogia, próprios do discurso da Negritude, mas, sobretudo, abre caminho para uma nova problemática: autocriação e autoprocriação, ${ }^{29}$ quando a tensão entre o eu e o outro, próprios do discurso da Negritude, passa para um segundo plano, em virtude do que chama "evisceração". Se o discurso da Negritude era o discurso da comunidade, apoiado na diferença, sua intenção era o resgate da comunidade perdida sob um discurso de lamentações. Segundo Mbembe, Ouologuem aposta em um discurso do excesso e 
da imoderação, que se sobrepõe ao do luto e da lamentação, criando um discurso que corresponde a um espaço de turbulências, onde a realidade é um entrelaçamento de coisas.

A imagem incandescente que o fotógrafo Naldinho ${ }^{30}$ fez de Danielly no Ato a Favor da Vida - ocorrido em fevereiro de 2014, durante uma ocupação militar da Maré - é de um corpoenfrentamento, corpo-mulher e corpo-coragem, que o fotógrafo lança atravessando o corpo negro, que insiste e reclama, aos gritos, o direito de autocriação. (Foto 7)

Assim também são as performances da artista Musa Michelle Mattiuzzi, sobretudo aquelas em que, como o escravo de Debret, usa a máscara da violência escravista. Em Mattiuzzi, porém, pulsa o entrelaçamento de gênero, raça e corpo, uma verdadeira turbulência, que ultrapassa o discurso da lamentação, impondo-se como excesso e imponderação. A força de suas imagensperformance, próxima do que Walter Mignolo ${ }^{31}$ teorizou como um pensamento fronteiriço, está na afirmação biográfica do corpo negro do Terceiro Mundo, que se sustenta ao mesmo tempo como corpo racializado, perpassado por histórias locais, marcadas pela colonialidade, mas se sustenta, também, pela consciência migrante dos que habitam as fronteiras e as rotas de dispersão, criando condições para a descolonização. Como no texto de James Baldwin, Remember this house, que o cineaste haitiano Raoul Peck usou como roteiro para o filme Eu não sou seu negro, Mattiuzzi cria para si uma imagem e um lugar turbulento e disperso, que nem sempre correspondem àqueles que a história e a história da arte esperam, mas que se apresentam como verdadeiras imagens dialéticas, imagens clarão. (Foto 8)

\section{NOTAS}

01. O texto faz parte da pesquisa de pós-doutorado Políticas da memória: estudos sobre colonialismo e pós-colonialismo na América Latina, desenvolvida no IEL/Unicamp e foi parcialmente apresentada no XXXIV Colóquio do Comitê Brasileiro de História da Arte, Campinas, 2016.

02. Fanon, Frantz. Pele negra, máscaras brancas. Salvador, EDUFBA, 2008.

03. Bhabha, H. O local da cultura. Belo Horizonte:
Ed. UFMG, 2005, p. 72.

04. Benjamin, W. Sobre o conceito de história. Tese 8. In. Walter Benjamin: obras escolhidas. Magia e técnica, arte e política. São Paulo: Ed. Brasiliense, 1985, p. 226.

05. Huber, Sacha. Louis quem? O que você deveria saber sobre Louis Agassiz. In: Panoramas do Sul. Leituras: Perspectivas para outras geografias do pensamento. Organização Sabrina Moura. São Paulo: Edições Sesc São Paulo, Associação Cultural Videobrasil, 2015.

06. Peabody Museum of Ethnology and Archeology, de Harvard. Disponível em:

http://pmem.unix.fas.harvard.edu:8080/ peabody/view/objects/aslist/search\$0040/10/ title-desc?t:state:flow $=9 \mathrm{f} 88 \mathrm{bff} 1-\mathrm{aa} 65-$ 4169-aaa2-bec3ee178487. Acessado em $13 / 08 / 2016$.

07. Paulino, Rosana. Entrevista à autora, São Paulo, abril de 2016.

08. Frantz Fanon nasceu na Ilha da Martinica, em 1925. Formou-se em psiquiatria e filosofia na França, tornando-se uma referência nos estudos sobre racismo e colonização. Lutou no norte da África e na Europa durante a Segunda Guerra Mundial e na Frente de Libertação Nacional da Argélia. Dirigiu o Departamento de Psiquiatria do Hospital Blida-Joinville, hoje Hospital Frantz Fanon. Dedicou boa parte de sua existência à transformação das vidas dos condenados pelas instituições coloniais e racistas do mundo moderno.

09. Fanon, op. cit.

10. Löwy, 2005, op.cit.

11. A famosa foto intitulada "Todos negros" rendeu ao fotógrafo o Prêmio Esso de fotografia de 1983.

12. Revista de História da Biblioteca Nacional, ano 8, n. 88, jan. 2013.

13. "Entre a suástica e a palmatória". Disponível em: https://historiografianarede.wordpress. com/2013/01/11/entre-a-suastica-e-apalmatoria-historia-material-oral-culturaldigital-e-publica/. Acessado em: 19/08/2016.

14. Fazem parte do acervo do Museu Afro- 
Brasil, São Paulo. Disponível em: http:// www.museuafrobrasil.org.br. Acessado em: 20/04/2016.

15. Fanon, op. cit., p. 105.

16. Lacan, Jacques. O estádio no espelho como formador da função do eu, tal como nos é revelado na experiência psicanalítica. In. Escritos. Rio de Janeiro: Jorge Zahar Editores, 1998.

17. Fanon (op. cit., p. 134) observa que nem Freud, nem Adler, nem Jung pensaram, em suas pesquisas, nos negros. Só com Aimé Cesaire surge a reivindicação da negritude assumida.

18. Fanon, op. cit., p. 141.

19. Hall, Stuart. Da diáspora: identidades e mediações culturais. Belo Horizonte: Editora UFMG, 2011.

20. Cf. Moura, Sabrina. Paralelos e meredianos em rearranjo. In: Panoramas do Sul. Leituras: Perspectivas para outras geografias do pensamento. Organização Sabrina Moura. São Paulo: Edições Sesc São Paulo, Associação Cultural Videobrasil, 2015, p. 21.

21. Hall, op. cit.

22. Fanon, op. cit., p. 95.

23. Fanon, op. cit., p.187, 188.

24. Bhabha, op. cit., p. 70.

25. Idem.

26. Com essa frase Fanon termina o livro Pele negra, máscaras brancas.

27. Hall, Stuart. Que negro é esse na cultura negra? In: Hall, op. cit., p. 317.

28. Mbembe, op. cit., p. 219.

29. Mbembe, op. cit., p. 221.

30. Disponível em :

http://www.composicoespoliticas.com/blank-2. Acessado em 15/09/2016.

31. Mignolo, Walter. Geopolítica da sensibilidade y do conhecimento: sobre (de)colonialidad, piensamento fronterizo y desobediencia epistêmica. Linz: eipcp. Disponível em http://eipcp.net/transversal/0112/ mignolo/es. Acessado em 18/09/2016.

\section{REFERÊNCIAS BIBLIOGRÁFICAS}

- Benjamin, W. Sobre o conceito de história. In. Walter Benjamin: obras escolhidas. Magia e técnica, arte e política. São Paulo: Ed. Brasiliense, 1985

- Bhabha, H. O local da cultura. Belo Horizonte: Ed. UFMG, 2005.

- Fanon, Frantz. Pele negra, máscaras brancas. Salvador, EDUFBA, 2008.

- Hall, Stuart. Da diáspora: identidades e mediações culturais. Belo Horizonte: Editora UFMG, 2011.

- Lacan, Jacques. O estádio no espelho como formador da função do eu, tal como nos é revelado na experiência psicanalítica. In. Escritos. Rio de Janeiro: Jorge Zahar Editores, 1998.

- Mignolo, Walter. Geopolítica da sensibilidade y do conhecimento: sobre (de)colonialidad, piensamento fronterizo y desobediencia epistêmica. Linz: eipcp. Disponível em http:// eipcp.net/transversal/0112/mignolo/es.

- Moura, Sabrina. (Org.) Panoramas do Sul. Leituras: Perspectivas para outras geografias do pensamento. São Paulo: Edições Sesc São Paulo, Associação Cultural Videobrasil, 2015.

\section{SOBRE A AUTORA}

Sheila Cabo Geraldo é pesquisadora e professora de História da Arte no Programa de Pós-graduação em Artes (PPGArtes) da Universidade do Estado do Rio de Janeiro (UERJ). Fez pós-doutoramento pela Universidade Complutense de Madri (UCM), em 2007/2008, doutoradoem História Contemporânea na Universidade Federal Fluminense (UFF), em 2001, mestrado em História Social da Cultura na Pontifícia Universidade Católica do Rio (PUC-Rio) em 1995. Organizou os livros: Trânsito entre Arte e Política (Quartet/Faperj), em 2012; Narrativas e Subjetividades - em conjunto com Luis Cláudio da Costa (Quartet), em 2012 e Fronteiras: arte, imagem, história. Beco do Azougue, em 2014. Atualmente desenvolve pesquisa sobre políticas da memória e estudos sobre colonialismo e pós-colonialismo na América Latina. 